\title{
Genetic and biochemical study of dual hereditary jaundice: Dubin-Johnson and Gilbert's syndromes. Haplotyping and founder effect of deletion in ABCC2
}

Lenka Slachtova, Ondrej Seda, Jana Behunova, Martin Mistrik and Pavel Martasek

European Journal of Human Genetics (2016) 24, 1515; doi:10.1038/ejhg.2016.51

Correction to: European Journal of Human Genetics (2016) 24, 704-709; doi:10.1038/ejhg.2015.181; published online 9 September 2015

Post publication, the authors realised that they had omitted the following acknowledgement:
PM is also supported by Grant Agency of Czech Republic (14-36804G).

The authors would like to apologise for this omission.

\section{Guidelines for diagnostic next-generation sequencing}

Gert Matthijs, Erika Souche, Mariëlle Alders, Anniek Corveleyn, Sebastian Eck, Ilse Feenstra, Valérie Race, Erik Sistermans, Marc Sturm, Marjan Weiss, Helger Yntema, Egbert Bakker, Hans Scheffer and Peter Bauer

European Journal of Human Genetics (2016) 24, 1515; doi:10.1038/ejhg.2016.63

Correction to: European Journal of Human Genetics (2016) 24, 2-5; doi:10.1038/ejhg.2015.226; published online 28 October 2015
Following the publication of this article, the authors wish to append a Supplementary file. This information can be found on European Journal of Human Genetics website http://www.nature. com/ejhg.

\section{Years of predictive testing for Huntington's disease: the experience of the UK Huntington's Prediction Consortium}

Sheharyar S Baig, Mark Strong, Elisabeth Rosser, Nicola V Taverner, Ruth Glew, Zosia Miedzybrodzka, Angus Clarke, David Craufurd, UK Huntington's Disease Prediction Consortium and Oliver W Quarrell

European Journal of Human Genetics (2016) 24, 1515; doi:10.1038/ejhg.2016.81

Correction to: European Journal of Human Genetics (2016) 24, 1396-1402; doi:10.1038/ejhg.2016.36; published online 11 May 2016

Post online publication the authors realised that they had made an error:
The sentence on page 2: 'In the first 5-year period.........but this changed significantly in the last 5 -year period with $51 \%$ positive and $49 \%$ negative $\left(\chi^{2}=20.6, P<0.0001\right)$ ' should read: 'In the first 5-year period.........but this changed significantly in the last 5-year period with $49 \%$ positive and $51 \%$ negative $\left(\chi^{2}=20.6, P<0.0001\right)^{\prime}$. 